\title{
A Novel Approach to Minimize Energy Requirements and Maximize Biomass Utilization of the Sugarcane Harvesting System in Sri Lanka
}

\author{
Thilanka Ariyawansha 1,2®, Dimuthu Abeyrathna ${ }^{2}$, Buddhika Kulasekara ${ }^{3}$, \\ Devananda Pottawela ${ }^{4}$, Dinesh Kodithuwakku ${ }^{5}$, Sandya Ariyawansha ${ }^{5}$, Natasha Sewwandi ${ }^{6}$, \\ WBMAC Bandara ${ }^{7}(D)$, Tofael Ahamed ${ }^{8}$ and Ryozo Noguchi ${ }^{8, *(D)}$ \\ 1 Graduate School of Life and Environmental Sciences, University of Tsukuba, Tsukuba 305-8572, Japan; \\ ktariyawansha@gmail.com \\ 2 Division of Mechanization Technology, Sugarcane Research Institute, Uda Walawe 70190, Sri Lanka; \\ khdimuthu@gmail.com \\ 3 Division of Crop Nutrition, Sugarcane Research Institute, Uda Walawe 70190, Sri Lanka; \\ kulasekaraya@gmail.com \\ 4 Division of Technology Transfer and Development, Sugarcane Research Institute, \\ Uda Walawe 70190, Sri Lanka; pottaweladpw@gmail.com \\ 5 Economics Biometry \& IT Division, Sugarcane Research Institute, Uda Walawe 70190, Sri Lanka; \\ dinkodi@yahoo.co.uk (D.K.); asandyakumari@yahoo.com (S.A.) \\ 6 Processing Technology, Sugarcane Research Institute, Uda Walawe 70190, Sri Lanka; \\ natashasewwandi7@gmail.com \\ 7 Department of Regional Resource Environmental Engineering, Faculty of Agriculture, \\ University of the Ryukyus, Okinawa 903-0213, Japan; chathu.anushk@gmail.com \\ 8 Faculty of Life and Environmental Sciences, University of Tsukuba, Tsukuba, Ibaraki 305-8572, Japan; \\ tofael.ahamed.gp@u.tsukuba.ac.jp \\ * Correspondence: noguchi.ryozo.gm@u.tsukuba.ac.jp; Tel.: +81-298534697
}

Received: 19 February 2020; Accepted: 20 March 2020; Published: 22 March 2020

check for updates

\begin{abstract}
Sugarcane harvesting requires a significant amount of energy and time to manage dry leaves after the harvesting process. Therefore, the objective of this study was to minimize the energy requirement to process the cane and dry leaves' harvesting (CDLH) for sugarcane while, at the same time, maximizing sugar production from cane and energy from dry leaves in Sri Lanka. The CDLH was conceptualized using a novel approach to optimize sugarcane harvesting to maximize biomass supply for energy production while reducing supply chain sugar-loss. The CDLH was investigated for manual harvesting capacity, energy consumption, sugar loss, and biomass energy potential. It was observed that CDLH consumed higher energy compared to the present practices of harvesting. However, the energy used for fieldwork was reduced because of the shifting of cane chopping and cleaning from the field to the factory. Low bulk density of the harvested cane of the CDLH system had a higher energy requirement in transportation. Comparatively, CDLH showed higher biomass energy potential and less sugar loss. High energy potential increases the energy potential to consumption ratio compared to the existing method. Therefore, the theoretical evaluation showed that the CDLH system can produce more than $20 \mathrm{~kg}$ of sugar and $879 \mathrm{MJ}$ of electricity when processing $1 \mathrm{t}$ of sugarcane.
\end{abstract}

Keywords: biomass; cane-energy; cogeneration; sugar; sugarcane harvesting; Sri Lanka 


\section{Introduction}

Table sugar is one of the value-added products from sugarcane (Saccharum officinarum). Nowadays, cane industries also produce electricity, ethanol, and other value-added products, besides the primary outcome of sugar [1-3]. World sugar production is projected to grow by $2.1 \%$ annually. Higher increases are expected from the developing countries with $79 \%$ of the global output in 2025 [4]. The sugarcane industry in Sri Lanka is one of the fast-growing sectors within the next few decades with a target of reducing sugar imports, increasing biomass energy generation, raising income, and employment generation [5]. The Sri Lankan government along with the sugarcane industries has implemented the Sri Lanka sugar sector development policy (SSDP) to increase current milling and cogeneration capacity to maximize the self-sufficiency in sugar and increase electricity generation using biomass.

The present total milling capacity of the Sri Lanka sugar industry is 6550 TCD (tonnes of cane per day) [6]. According to the SSDP, the government collaborated with the Sri Lankan sugar industry and its related investors have begun to increase this capacity up to 40,500 TCD with a total cogeneration capacity of $123 \mathrm{MW}$ in 2030. According to Keerthipala [6], the present Sri Lankan sugar industry is facing a severe problem of a lack of a workforce during sugarcane harvesting. Harvesting operations occupy more than $30 \%$ of the cost of production for sugarcane in Sri Lanka [5]. Considering this, the industry has attempted to mechanize the sugarcane harvesting using imported self-propelled sugarcane chopper harvesters. However, this was not successful because of the inappropriate uses of those harvesters under local conditions.

The productivity of sugarcane chopper harvesting depends on the availability of the best cultural practices such as land layout, earthing up and irrigation practices. Furthermore, a harvester's technical points are highly influenced by skilled operators and varieties of sugarcane that are suitable for mechanized harvestings, like erect cane and low-fiber cane [7]. However, selecting low-fiber sugarcane varieties targeting mechanized harvesting can reduce the cane energy potential, and will affect the energy cane concept. The energy cane is a concept of improving the fiber content of sugarcane through the genetic improvement of cane [8]. However, utilization of this cane can be done efficiently with the modification of the conventional sugarcane harvesting system [9]. Sugarcane harvesting machines are large and heavy which leads to soil compactions [10] and also have a high power chopping and cleaning system which consumes $43 \%$ of hydraulic energy used for harvesting systems (cutter, chopper, extractor fan, and elevator) [9]. Even if there is a cleaning system, still inside the harvester are found significant extraneous materials in harvested cane, which leads to reduced sugar recovery and increased costs of the milling process [11]. Also, chopping is not appropriate for the areas that do not have an on-time supply and processing in harvesting systems, because delaying the processing of chopped cane leads to higher sugar losses due to sugar degradation [12]. In this regard, an appropriate harvesting system is essential to optimize resource utilization and improve the productivity in sugarcane harvesting for small-scale farming systems.

There are around 19\% to 35\% (wet basis) trash (tops and dry leaves) left in the field after a harvest [13]. The dry matter yield of the trash was about $16 \%$ of the total cane supply to the factory [14]. The trash left in the field affect irrigation furrowing [15] and land preparation for the next crop. Therefore, growers tend to burn the trash or use another set of machines to cut the trash into small particles or gather and remove it, which leads to higher energy consumption in the field [16]. According to Trivelin et al. [17], the dry sugarcane leaves could be used for energy generation because they contain less moisture and higher fiber compared to the tops, and so have higher energy potential. Sugarcane tops could be used for soil improvement since they have higher nutrition, moisture, and degradation rate compared to the dry leaves. Also, the use of $50 \%$ sugarcane trash available in the field for cogeneration could help to double the electricity export from the sugar factory [18]. As well, partial removal of the dry leaves would support the sugarcane yield [19]. Therefore, collecting annoying dry leaves that affect crop management could contribute to energy generation. This would be one of the good solutions to reduce burning infield of dry leaves while keeping sugarcane tops for soil improvement. 
All past discussions have mentioned that the sugarcane harvesting system has some significant drawbacks in terms of biomass utilization, sugar recovery, and difficulty to use small land areas in developing countries. There is a big research gap to improve the sugarcane harvester in ways that are appropriate for efficient sugarcane harvesting while supplying biomass for energy.

Therefore, the goal of this study was to create a concept using a novel approach to minimize energy requirement in sugarcane harvesting for improving sugar recovery and maximizing biomass supply. Furthermore, at the same time, theoretically we evaluate the novel approach with the existing cane harvesting and supply system in Sri Lanka. To achieve the goal of this research, we formulated specific objectives to obtain the required data from the Sri Lankan sugar industry. These specific objectives were to evaluate the existing manual and mechanical harvesting system in point of harvesting capacity, cane quality, and ability to supply the biomass for cogeneration.

\section{Materials and Methods}

Sugar production and bioenergy generation from sugarcane is a complex process combining agricultural practices to line up with processing at a large-scale factory level. The sugar manufacturing flow process with the system boundary for the Sri Lankan sugar industry is shown in Figure 1. In this study, we focused on the novel approach to improve the current harvesting practice suitable for supply cane and dry leaves for sugar and energy production. In sync, the novel concept minimizes post-harvest sugar losses and the reduction of fuel consumption for harvesting operations. We investigated the harvesting system theoretically according to four considerations: 1 . harvesting capacity, 2. energy consumption in harvesting, 3. biomass available for cogeneration, and 4. post-harvest sugar losses. To address the issues in harvesting and supply, which were discussed in the introduction, we developed a new harvesting concept called cane and dry leaves harvesting (CDLH). CDLH was comparatively investigated over the existing harvesting process called cleaned cane harvesting $(\mathrm{CCH})$. $\mathrm{CCH}$ is a method to supply cleaned cane (only cane stalk or billets without any extraneous materials) to the factory without trash by means of manual or mechanical harvesting. To collect the data required for this investigation, we studied the existing sugarcane harvesting in Sri Lanka and described in Section 2.1.

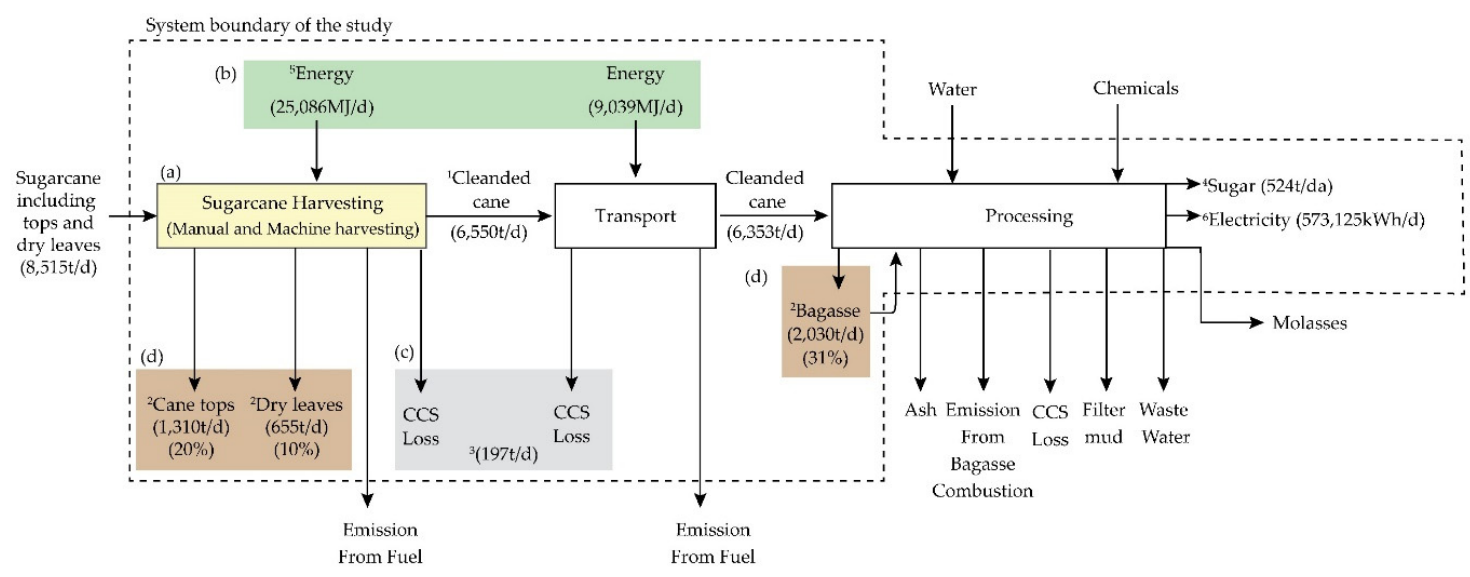

Figure 1. The system boundary of the study based on Sri Lankan sugarcane industry. (a) Sugarcane harvesting; (b) energy use; (c) commercial cane sugar (CCS) losses and (d) biomass potential; ${ }^{1}$ Keerthipala [6]; ${ }^{2}$ estimated using data available in Sugarcane Research institute based on total cane stalk harvested; ${ }^{3}$ estimated based on data available in Weerasinghe, et al., [20] and Solomon [21]; ${ }^{4}$ estimated using sugar industry statistic in Sri Lanka; ${ }^{5}$ theoretical energy need for cutting, cleaning, chopping and loading only; ${ }^{6}$ estimated using data available in Brizmohun, et al., [1]. 


\subsection{Sugarcane Harvesting}

Sugarcane harvesting in Sri Lanka is practiced by either manual or mechanical means. Manual harvesting is the more common method, but mechanical harvesting is becoming more popular since the accute labor shortages during harvesting of sugarcane. To obtain a whole picture of the harvesting system in Sri Lanka, we studied the existing harvesting practices separately.

\subsubsection{Manual Harvesting}

In manual harvesting, human power is used to harvest the sugarcane. The manual cane harvester (labor) uses a special knife to cut the sugarcane from the lowest position of the cane called base cutting. The next step of the manual harvesting is to remove the tops of the cane stalk. Finally, remaining dry leaves of the cane stalks are removed using the same knife. We recorded the time taken for base and top cutting and removing dry leaves in 100 random samples while manual cane harvesters were used for harvesting at the sugarcane fields in Uda Walawe, Sri Lanka, in April 2018. The weight and length of each harvested cane stalk were recorded instantly using the portable electronic weighing machine (resolution $1 \mathrm{~g}$ ) and measuring tape (resolution $1 \mathrm{~mm}$ ). In manual harvesting, cleaned canes were supplied to the factory since all the dry leaves in the cane stalk were removed. The sugarcane dry leaves and tops removed from each cane stalk were recorded. While recording manual harvesting time, we omitted the time taken for resting and other non-harvesting activities. The collected data were used to evaluate manual harvesting capacity.

\subsubsection{Mechanical Harvesting}

Mechanical harvesting is very new to Sri Lanka, and very few harvesting machines are used to harvest the cane. Most of these harvesting machines are small combine-chopper harvesters. The arrangement of the different systems of a small combine-chopper harvester is illustrated in Figure 2. The hydraulic energy consumption for the base cutter $(0.61 \mathrm{MJ} / \mathrm{t})$, chopper $(0.3 \mathrm{MJ} / \mathrm{t})$, extractor fan $(0.3$ $\mathrm{MJ} / \mathrm{t})$ and elevator $(0.18 \mathrm{MJ} / \mathrm{t})$ was reported by Mathanker et al. [9] when the machine pour rate is $132.65 \mathrm{t} / \mathrm{h}$. The moving energy could be calculated based on the speed of the harvester, weight and time taken for harvest $1 \mathrm{t}$ of cane. Therefore, the total energy requirement for the machine would be the sum of the energy needed for the base cutter, chopper, extractor fan, elevator plus the energy needed for moving the machine. The data regarding the available numbers of sugarcane harvesters with its actual average harvesting capacities were collected from the industry harvesting records from the sugarcane research institute in Sri Lanka. We measured the working speed of the harvester, theoretical harvesting capacity, visible impurities in the harvested cane, and infield visible cane losses when the combine-chopper sugarcane harvester was used in Sri Lanka. Those data were collected during normal harvesting at Sevanagala Sri Lanka. To measure the working speed, we recorded the time required to travel the known distance of the harvester along the furrows. We repeated the same measuring method in different rows with 10 replications, and the average was calculated. To measure the visible impurities, we collected harvested cane into plastic trays $(80 \times 50 \times 40 \mathrm{~mm})$ placed on the trailer as 10 random samples. We separated good cane and visible trash and then, based on the weight, the impurities content was calculated. To measure visible infield cane losses, we selected 10 random locations from the harvested field. Then $4 \mathrm{~m}^{2}$ area was isolated from the selected points, and all the visible trash and cane available in that location were collected carefully by hand. The trash and cane were separated and, based on the weight, the visible cane losses were calculated. The reduced sugar content in the harvested cane was estimated just after $24 \mathrm{~h}$ and $48 \mathrm{~h}$ using the Lane-Eynon method [22] to understand post-harvest losses of sugar compared to manual harvesting. 


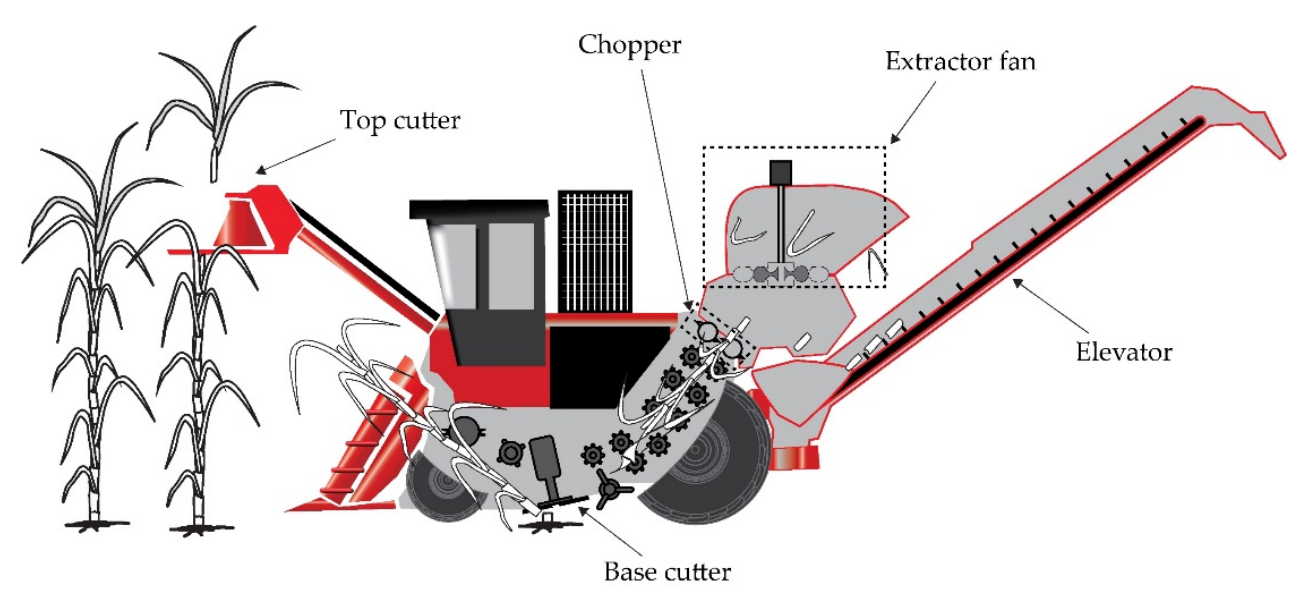

Figure 2. Different systems of the combine-chopper harvester used for cleaned cane harvesting (CCH).

\subsection{Cane and Dry Leaves Harvesting (CDLH) Concept}

According to industry information, the average actual processing capacity is $73 \%-80 \%$ in Sri Lanka. One of the main issues for this was labor shortages, especially for harvesting and loading [6]. Thus, the industry has focused on the mechanization of sugarcane harvesting. However, the undulated, smaller lands and inappropriate crop management caused a poor performance in imported harvesters. Therefore, the sugar industry is facing issues related to rehabilitating lands and improved crop management practices suitable for mechanization. According to the SSDP, the processing capacity of the country will be increased up to 28,000 TCD in the year 2025, and then would be increased up to 40,500 TCD in 2030. With this increased capacity, the industry attempts to install 123 MW cogeneration capacities. But they have identified that the cogeneration would run out in the non-crushing season due to lack of bagasse. Therefore, industry targets are to obtain wood biomass such as Gliricidia (Gliricidia sepium) for cogeneration. Nonetheless, dry leaves remaining after harvest are another option for supplying more biomass for cogeneration. Therefore, we developed an alternative scenario called cane and dry leaves harvesting (CDLH), focusing on increasing the efficiency of the sugarcane harvesting, minimizing conventional fuel use, more biomass supply for cogeneration, and the increasing sugar recovery. $\mathrm{CCH}$ and $\mathrm{CDLH}$ are illustrated in Figure 3. In the CDLH scenario, we considered sugarcane was cut from the base and then the tops were removed in the field, but dry leaves were not removed since it consumed considerable time and energy in both manual and mechanical conditions. The removed tops were left in the field because tops contain less fiber, high nutrients and moisture compared to the dry leaves, and it is not suitable for energy generation but suitable for soil improvements. Also, partial removal of the dry leaves would be important for better yield $[17,19,23]$. In the CDLH system, the harvested cane with dry leaves could be loaded to the trailer and transported to the factory. In the factory, we considered installing a new set of machines to separate the cane and dry leaves. The function of these machines was similar to the cane chopping and dry leaves removing of the conventional sugarcane combine-chopper harvester. However, in CDLH we do not need to cut the sugarcane into small sections like billets. This is because just after cleaning, the cane is sent to the mill and dry leaves are sent to the boiler for energy production. This set of machines would be installed before the cane shredder, and it would be run using energy generated from biomass at the factory. 


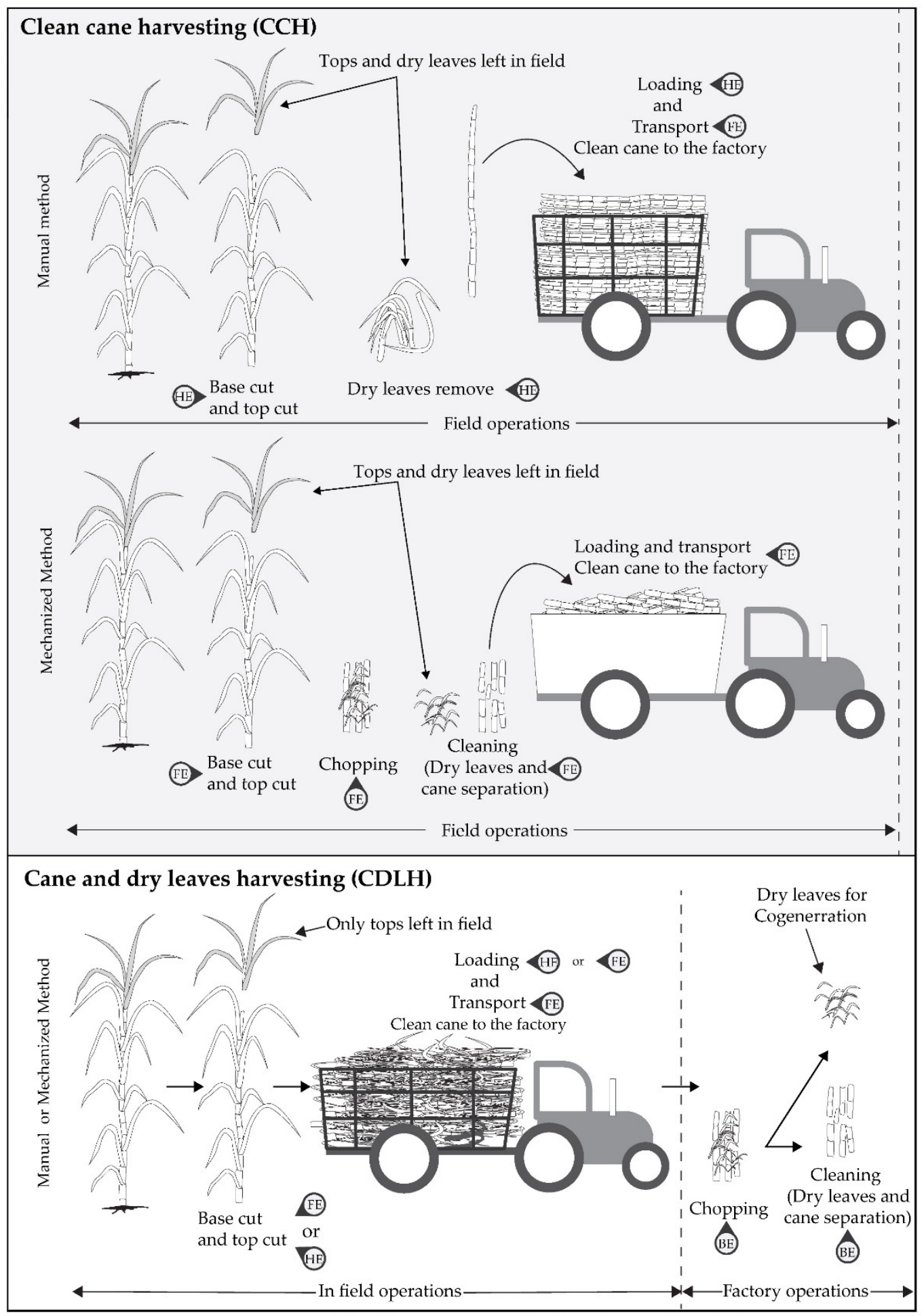

HE - Human energy, FE = Fuel Energy (Diesel), BE - Biomass Energy

Figure 3. Cleaned cane harvesting $(\mathrm{CCH})$ and cane and dry leaves' harvesting (CDLH) systems.

Based on the process flow described in Figure 3, we analyzed comparatively the theoretical harvesting capacity, energy consumption, energy recovery, and potential sugar recovery using a set of theories described in the next section. The harvesting capacity, energy consumption, sugar recovery, and energy potential were reported for the processing of one tonne of cleaned cane (tcc). 


\subsubsection{Theoretical Harvesting Capacity}

Field evaluation data was collected to calculate the harvesting capacity for manual and mechanical harvesting process. The manual harvesting capacity is the amount of sugarcane that can be harvested by one person per day using Equation (1).

$$
M n H C=\frac{3.6 \times t_{d} \times W_{c}}{t_{s}}
$$

where, $\mathrm{MnHC}$ is the manual harvesting capacity (tcc/day/person), $t_{d}$ is the working hours per $24 \mathrm{~h}$ $(\mathrm{h} / \mathrm{d}), W_{c}$ is the average weight of the one cane stalk $(\mathrm{kg}), t_{s}$ is the time required to harvest one cane stalk (s). The theoretical mechanical harvesting capacity was calculated for single raw harvesters using Equation (2).

$$
\mathrm{McHC}=3.6 \times t_{d} \times Y_{u} \times V_{h}
$$

where, $\mathrm{McHC}$ is the mechanical harvesting capacity (tcc/day), $Y_{u}$ is the unit yield along the raw $(\mathrm{kg} / \mathrm{m})$, $V_{h}$ is the average speed of the harvester $(\mathrm{m} / \mathrm{s})$. When measuring the $Y_{u}$ and $V_{h}$, traveled distance and time required for filling the cane infielder were measured. When recording the time, the time required for turning, stopping, adjustments were omitted since we needed to measure maximum possible harvesting capacity. The weight of the harvested cane and trailer was measured using weighbridge available in the Sevanagala sugar factory.

\subsubsection{Theoretical Energy Consumption}

The energy requirement for supplying one tonne of cane was calculated in each major step of harvesting and supply system using the following equations and methods.

Cutting energy: the cutting energy can be calculated multiplying specific cutting energy by area of the cut. Therefore, the bottom and top cutting energy were calculated using Equation (3).

$$
C t E=\frac{250 \times \pi \times D_{B C}^{2} \times S E_{C}}{W_{c S}}
$$

where, $C t E$ is the energy needs to cut the sugarcane from base or top $(\mathrm{J} / \mathrm{tcc}), D_{B C}$ is the average diameter of the cane stalk $(\mathrm{mm}) . S E_{c}$ is the specific cutting energy $\left(\mathrm{J} / \mathrm{mm}^{2}\right), W_{C S}$ is the average weight of a cane stalk at harvest $(\mathrm{kg})$.

Chopping energy: chopping is the method of cutting the sugarcane into small sections called billets with chopping harvesters. In chopping, one sugarcane stalk is cut from several positions. Therefore, total cutting energy is the sum of all the energy required to cut the sugarcane from each position. The theoretical energy required to produce the billets were calculated using Equation (4). In CDLH, not only sugarcane but dry leaves were also cut into small parts, and the length was similar to the billets. The energy required for chopping dry leaves ( $D L C E$ —dry leaf cutting energy) was calculated using Equation (5). DLCE was estimated based on the specific cutting energy and cross-section area of each cut. For the calculation purpose, specific cutting energy of the dry leaves was estimated using the method described in Ariyawansha et al. and Chandio et al. [24,25]. The cross-section area of the cut was estimated using a Vernier caliper, assuming the leaf cross-section area was rectangular in each cut. The number of cuts of cane or dry leaves was estimated using Equation (6).

$$
\begin{gathered}
C C E=\frac{\sum_{1}^{i}\left(D_{n}^{2} \times S E_{n}\right) \times(250 \pi)}{W_{C S}} \\
D L C H=1000 \times A \times\left(\frac{S E_{D L}}{W_{C S}}\right)
\end{gathered}
$$




$$
i=\left(\frac{l_{c}}{l_{b}}\right)-1
$$

where, CCE is the energy required for chopping cane $(\mathrm{J} / \mathrm{tcc}), i$ is the number of cuts, $D_{n}$ is the diameter of each $\left(n\right.$ th) cutting/chopping point, $S E_{n}$ is the specific cutting energy $n$th section $\left(\mathrm{J} / \mathrm{mm}^{2}\right), D L C E$ is the dry leaf cutting energy $(\mathrm{J} / \mathrm{tcc}), A$ is the cross-section area of the cut surface of the dry leaves $\left(\mathrm{mm}^{2}\right), S E_{D L}$ is the specific cutting energy of the sugarcane trash $\left(\mathrm{J} / \mathrm{mm}^{2}\right), l_{c}$ is the average length of the cane/dry leaves $(\mathrm{cm}), l_{b}$ is the average length of the cane billet $(\mathrm{cm})$.

Cleaning energy: the energy required to produce the airflow from the extractor fan of the sugarcane harvester for cleaning the chopped cane was calculated using Equation (7) [26].

$$
E_{f}=P_{t} Q_{a} t_{h}
$$

where, $E_{f}$ is the energy required for cleaning the cane $(\mathrm{kJ} / \mathrm{tcc}), P_{t}$ is the total pressure $(\mathrm{kPa}), Q_{a}$ is the airflow rate $\left(\mathrm{m}^{3} / \mathrm{s}\right), t_{h}$ is the time required to harvest one tonne of cleaned cane (s).

Loading and transport energy: material loading energy for one tonne of clean cane was calculated using Equation (8). The energy required to travel in a distance is the product of applied force and distance. In a vehicle, the applied force is equal to the sum of rolling resistance, aerodynamic drag, and gradient force when it is at a constant speed [27]. The majority of the roads where sugarcane cultivation areas in Sri Lanka are earthen roads. Therefore, the tractor's speed for transporting sugarcane is lower. Therefore, the aerodynamic drag force is very small compared to the rolling resistance, assuming the vehicle (tractor with cane loaded wagon) is running in flat soil road at a constant speed and the applied force is equal to the rolling resistance. The rolling resistance is the product of the coefficient of rolling resistance, the total weight of the vehicle, and the acceleration of gravity [28]. Therefore, the required energy for transportation of one tonne of clean cane was calculated using Equation (9). We assumed all other factors affecting the rolling resistance of the coefficient similar to CCH and CDLH. Et is the transport energy requirement $(\mathrm{kJ} / \mathrm{tcc} / \mathrm{km})$ was calculated using Equation (8).

$$
\begin{gathered}
E l=m \times g \times h\left(\frac{100}{100-P_{D L}}\right) \\
E t=\frac{C_{r} \times m_{t} \times g \times l}{m_{c c}}
\end{gathered}
$$

where, $E l$ is the loading energy $(\mathrm{kJ} / \mathrm{tcc}), m$ is the cane and dry leaves weight $(\mathrm{t}), P_{D L}$ is the percentage of dry leaves (\%), $g$ is the acceleration due to gravity $\left(9.81 \mathrm{~m} / \mathrm{s}^{2}\right), h$ is the height of the lift $(\mathrm{m}), C_{r}$ is the coefficient of rolling resistance (0.08 for soil [28]), $m_{t}$ is the total weight $(\mathrm{t}), l$ is the length $(1000 \mathrm{~m}), m_{\mathcal{C}}$ is the weight of clean cane $(t)$ and was calculated from Equation (10).

$$
m_{c c}=m \times\left(\frac{100-P_{D L}}{100}\right)
$$

The $m_{t}$ is the sum of the vehicle's empty weight and cane weight, including trash. Therefore, $m_{t}$ was calculated using Equation (11).

$$
m_{t}=m_{v}+\left(v \times \rho_{b}\right)
$$

where, $m_{v}$ is the weight of the vehicle $(\mathrm{t}), \mathrm{v}$ is the volume of the wagon $\left(\mathrm{m}^{3}\right), \rho_{b}$ is the bulk density of the cane $\left(t / \mathrm{m}^{3}\right)$. To estimate the transportation energy for a certain distance, the value taken from Equation (9) was multiplied by the distance of transportation. The transport energy may be different from the different loading conditions of the cane. When transporting the cane billets, it would be compacted very well without extra effort, so bulk density would be higher. When we load the whole cane, it would be more difficult to compact without extra effort, then the bulk density would be less. Therefore, we calculated transport energy for normal loading and compacted loading (Improved bulk density (IBD)) conditions. The bulk density was measured after filling the cane into a trailer with 
known volume and weight. The volume of the trailer was calculated after obtaining the dimensions of the trailer. The weight of the cane was taken from the weighing bridge after measuring the trailer with the cane and without the cane. Then we calculated the variation of the total energy (TE) consumption as the energy needed for cutting, chopping, cleaning, loading, and transportation over the distance up to $25 \mathrm{~km}$. Also, we calculated field energy (FE) consumption. FE is the energy used for machinery during harvesting and delivering the cane to the factory, and therefore FE is supplied by diesel. In $\mathrm{CDLH}$, we propose to move the cleaning and chopping system to the factory. Therefore, in CDLH, the energy needed for cleaning and chopping would be supplied from the factory as biomass energy.

\subsubsection{Potential Energy Recovery}

In $\mathrm{CCH}$, the only available biomass for cogeneration was bagasse, but in $\mathrm{CDLH}$, bagasse and dry leaves were available for cogeneration. The bagasse availability was estimated using the industry statistics of the Sevanagala, Palwatta, and Higurana sugar industries. The higher heating value of each biomass at constant pressure was estimated using Equation (12) [29].

$$
L H V=H H V \times(1-M)-2.443 \times M
$$

where $L H V$ is the lower heat of wet biomass at constant pressure $(\mathrm{MJ} / \mathrm{kg}), M$ is the moisture content of the biomass (mass fraction). A field trial was conducted to estimate the dry leaves available in the commonly used sugarcane variety (SL 96328) in Sri Lanka. We harvested 100 of the sugarcane stalks randomly, then dry leaves and tops were separated from the cane stalk, and the weight of the dry leaves was measured. The moisture content of the dry leaves was determined using the oven-dry method. We considered the higher heating values of the bagasse and dry leaves as $18.32 \mathrm{MJ} / \mathrm{kg}$ and $18.87 \mathrm{MJ} / \mathrm{kg}$ respectively [30]. Based on the available quantities of bagasse and dry leaves and higher heating value (HHV), the recoverable energy potential of $\mathrm{CCH}$ and $\mathrm{CDLH}$ was estimated. To estimate the overall energy profitability of the $\mathrm{CCH}$ and $\mathrm{CDLH}$, the energy potential to consumption ratio (EPCR) was calculated using the Equation (13). EPCR is important because it gave a clear explanation of the energy profitability of the system. Thus, it is very important for comparing two systems in a very effective way. We use the EPCR instead of the well-established EROI (energy return on investment) for understanding energy productivity. This is because Hall et al. [31] reported that there were big differences in the EROI for biofuel. One of the reasons for this difference is the use of different boundary conditions for calculating the EROI. Therefore, we did not use the EROI since CDLH is a novel concept and is not well-established at this stage of commercial level. Thus, reporting values with theoretical conditions may differ from actual conditions. Therefore, we described the energy productivity based on the term similar to EROI but with a different approach. EPCR is calculated using Equation (13):

$$
E P C R=\frac{T E P}{T E C}
$$

where, TEP is the total theoretical energy potential from bagasse and trash. TEC is the total theoretical energy consumption for harvesting and supply. When calculating the TEP for $\mathrm{CCH}$, the value taken from Equation (12) for bagasse was used since $\mathrm{CCH}$ only provides bagasse for energy generation. However, CDLH provides bagasse and dry leaves for energy generation, hence TEP in CDLH is equal to the sum of $L H V \mathrm{~s}$ of bagasse and dry leaves. In this study, we considered TEP is the maximum available energy without generation loss. Therefore, this value is considered an ideal value. TEP available in CCH and CDLH can be converted to heat and electricity through cogeneration. After the use of heat and electricity for sugarcane processing, the excess energy could be export as electricity. To calculate the exportable electricity, we multiplied TEP using combined cogeneration efficiency and reduced the energy used for sugarcane processing (heat and electricity) in both $\mathrm{CCH}$ and CDLH. We assumed combined cogeneration efficiency of the boiler was 85\% [32] and the generator was as $96 \%$ [33]. TEC was the sum of base and top cutting, chopping, cleaning, loading, and transporting. 
Therefore, TEC would vary with the transport distance thus EPCR was changed with the distance of transportation. Therefore, to obtain a better understanding of the energy potential, we calculated the $E P C R$ with the transportation distance up to $25 \mathrm{~km}$.

\subsubsection{Sugar Recovery Potential}

To measure the sugar recovery potential, we experimented by measuring commercial cane sugar (CCS) with post-harvest delay. Eighteen number of sugarcane stalks were harvested randomly at a time. Among the 18 stalks, nine were harvested without dry leaves as described in $\mathrm{CCH}$, and the other nine were harvested with trash as CDLH. The Brix, Pol (polarization) values were measured using a digital refractometer (Atago RX-IP), and pol-digital polarimeter (Jasco-P2000) after sample taking from the top, middle and base of the three cane stalks in each harvesting method in every $24 \mathrm{~h}$ until $72 \mathrm{~h}$. The CCS was calculated using Equation (14) [34]:

$$
C C S=\frac{3 P}{2} \times\left(1-\left(\frac{(F+5)}{100}\right)\right)-\frac{B}{2} \times\left(1-\frac{(F+3)}{100}\right)
$$

where, CCS is the commercial cane sugar content (\%), $P$ is the Pol value (\%), $B$ is the Brix value (\%), $F$ is the fiber content (\%). Finally, the two systems were compared based on energy used for supplying the cane, available biomass energy, and sugar potential at $1 \mathrm{~km}$ transport distance. To obtain the general understanding of the economic status of those two methods over the transport distance, we calculated the net profit ratio (NPR) compared to the energy cost of supply using Equation (15). To calculate supply energy cost, we converted energy used for harvesting and transport of the cane into diesel equivalent (assuming $36 \mathrm{MJ}$ equal to $1 \mathrm{~L}$ of diesel). The cost of production of $1 \mathrm{~kg}$ of sugar without harvesting and transport energy was assumed $94 \mathrm{LKR} / \mathrm{kg}$. The total income was calculated based on the total sugar and energy produced from the factory. We assumed the selling price of the sugar was $96 \mathrm{LKR} / \mathrm{kg}$ (wholesale price) and energy was $25 \mathrm{LKR} / \mathrm{kWh}$.

$$
N P R=\frac{\text { Income }- \text { Cost of sugar }- \text { Cost of energy for cane supply }}{\text { Income }}
$$

\section{Results and Discussion}

SSDP is essential for sugarcane industry development in Sri Lanka. However, to realize this work, the sugarcane supply system must be timely, reliable, and capable of utilizing biomass in an effective way. To address the issues in the harvesting and biomass utilization, we introduced a sustainable harvesting practice called CDLH and theoretically evaluated compared to the $\mathrm{CCH}$. We used the data available in the sugarcane industry in Sri Lanka and data available in the literature for this model's calculations. However, depending on the situation, we conducted the required experiments to collect essential data in the following subsection.

\subsection{Sugarcane Harvesting in Sri Lanka}

Sugarcane harvesting in Sri Lanka only provides clean cane to the factory using manual harvesting since all the tops and dry leaves are removed before transportation. In mechanical harvesting, there are several constraints such as extraneous materials in harvested cane and sugar losses. The results showed that mechanical harvesting in Sri Lanka was 18\%, and it provided 1190 TCD (Table 1). The other cane requirement was supplied by manual harvesting, and it was about 5360 TCD. Therefore, manual harvesting was still dominant, and it was $82 \%$ of the total harvest in Sri Lanka. On the other hand, the agricultural population in Sri Lanka has been reducing due to people moving out of agriculture into other sectors such as industrial and service with higher salaries and simplicities of the works compared to harsh sugarcane harvesting [29]. Therefore, the availability of labor for sugarcane harvesting is drastically reduced. These results proved the statement given by the Keerthipala [6] regarding low factory capacity because of inadequate sugarcane supply due to the lack of labor for sugarcane 
harvesting. Focusing on appropriate solutions for cane and biomass harvesting and supply, we separately studied the current harvesting practice in Sri Lanka, and the results are described as follows:

Table 1. Present status of sugarcane mechanization level in Sri Lanka (2019 data).

\begin{tabular}{cccc}
\hline Harvester Model & Quantity (Nos.) & Actual Capacity $\mathbf{t} / \mathbf{d}$ & Total Harvesting (t/d) \\
\hline CASE Austoft 4000 & 5 & 70 & 350 \\
CASE Austoft 4000 Case++ & 6 & 80 & 480 \\
Shaktiman 3737 & 4 & 90 & 360 \\
Total machine harvesting capacity & - & - & 1170 \\
Total processing capacity & - & - & 6550 \\
Mechanization level of sugarcane & - & - & $18 \%$ \\
harvesting & & & \\
\hline
\end{tabular}

\subsubsection{Manual Harvesting}

In manual harvesting, when harvest one cane stalk, as shown in Figure 4, maximum time; $13.19 \pm 3.23 \mathrm{~s}$ was utilized for removing of dry leaves, and it was about $79 \%$ from total harvesting time. The minimum time; $0.93 \pm 0.2 \mathrm{~s}(5 \%)$ was used for top cutting. The time required for base cutting was $2.62 \pm 0.8 \mathrm{~s}$. The average weight of the harvested clean cane stalk was $1071 \pm 351 \mathrm{~g}$. Depending on these results, a person can harvest about 1.87 tonnes per day $(8 \mathrm{~h})$ theoretically. Hypothetically there should be a minimum of 2867 persons per day for harvesting sugarcane manually. But the field data shows the actual harvesting capacity of a person is about 1.0-1.5 tcc/day. Then the required number of persons for sugarcane harvesting would be between $3573-5360$ persons per day.

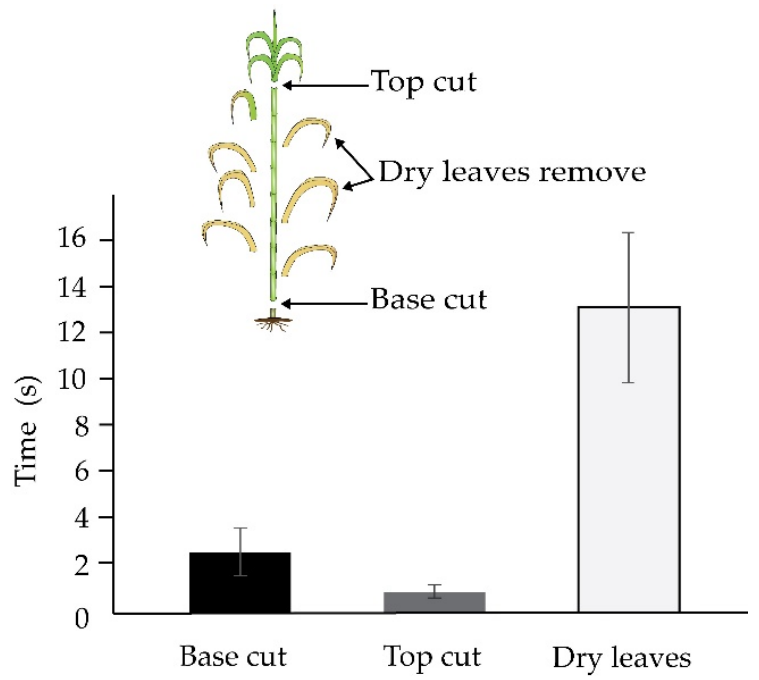

Figure 4. Time utilization for different activities when harvest one cane stalk in manual harvesting.

\subsubsection{Mechanical Harvesting}

Mechanical harvesting evaluation results showed that the average speed of the harvester was $0.76 \mathrm{~m} / \mathrm{s}(2.74 \mathrm{~km} / \mathrm{h})$ in the sugarcane field with a furrow length of $122 \mathrm{~m}$ without proper earthing up and with yield of $55 \mathrm{tcc} / \mathrm{ha}$. The extraneous materials content was $10.67 \%$ from the total harvest, and there were $3.75 \%$ trash and $6.91 \%$ dry leaves among the extraneous materials. According to Sugar Research Australia (2014) [7], extraneous materials would vary between $2 \%-15 \%$ when there is use of mechanical harvesting. The visible cane loss was $2.18 \mathrm{t} / \mathrm{ha}$. The visible loss includes billets, and no harvested cane is left in the field. Among the $2.8 \mathrm{t} / \mathrm{ha}, 1.75 \mathrm{t} / \mathrm{ha}$ was non-harvested cane stalk left in the field. As stated by Maria et al. [35], the visible billet loss was $0.84 \mathrm{t} / \mathrm{ha}$, but in this evaluation showed that billet loss was $1.05 \mathrm{t} / \mathrm{ha}$. Chopping and cleaning systems cause to lose the sugar and increase the extraneous materials under the different operating conditions of the harvester and crop conditions $[7,36]$. The reduced sugar content of the machine harvested chopped cane, and the manually 
harvested cane was $1.63 \%$ and $1.39 \%$, separately, $24 \mathrm{~h}$ after harvesting. It was increased up to $1.83 \%$ by machine and $1.80 \%$ manually in $72 \mathrm{~h}$ after harvesting. Increase rate of reducing sugar means increasing sugar degradation. Therefore, mechanical harvesting leads to increases in sugar degradation, especially in areas without proper supply systems. Based on the evaluation data, the maximum achievable theoretical harvesting capacity was $184 \mathrm{tcc} / \mathrm{da}$ assuming a harvester works without turning for $7142 \mathrm{~m}$ (distance travel for harvest 1 ha with raw spacing $1.4 \mathrm{~m}$ ) in $\mathrm{CCH}$. The importance of this data is to understand the maximum achievable limit for a future decision on land layout development. The industry data showed that the actual average harvesting capacity was $80 \mathrm{tcc} / \mathrm{da}$. The reason for this issue would be inappropriate land layout and crop management. In existing lands, a harvester spent more than $50 \%$ of its time turning and in base cutter adjustment because of inappropriate, row length, headlands, and poor or no earthing up. Sri Lankan sugarcane lands did not have a well-prepared land layout suitable for mechanization. The evaluation results showed harvesting capacity for the maximum row length. Therefore, it is essential to have land with maximum row length and enough headland to obtain maximum productivity from the modern harvester.

\subsection{Comparison of Cleaned Cane Harvesting (CCH) and Cane and Dry Leaves' Harvesting (CDLH)}

CDLH was the novel concept. Therefore, there were no actual configurations for collecting the data for analysis. To compare the novel concept with the existing method, we carried out the theoretical approaches to analyze the $\mathrm{CDLH}$ over $\mathrm{CCH}$. The data collected from the industry statistics, experiments, and literature used for comparative analysis are listed in Table 2.

Table 2. Data used for comparison of CCH and CDLH.

\begin{tabular}{|c|c|c|c|}
\hline Data & Value (SD) & Units & Data Source \\
\hline Working hours per day $\left(t_{d}\right)$ & 8 & $\mathrm{~h}$ & Filed examination \\
\hline Time required for harvest one cane stalk $\left(t_{s}\right)$ in $\mathrm{CCH}$ & $16.75( \pm 4.95)$ & $\mathrm{s}$ & Measured \\
\hline Time required for harvest one cane stalk $\left(t_{s}\right)$ in CDLH & $3.56( \pm 1.71)$ & s & Measured \\
\hline Weight of the one cane stalk & $1071.10( \pm 411)$ & $\mathrm{g}$ & Measured * \\
\hline Unit yield $\left(Y_{u}\right)$ along with the raw & 7.7 & $\mathrm{~kg} / \mathrm{m}$ & Calculated $* *$ \\
\hline Speed of the harvester & 0.76 & $\mathrm{~m} / \mathrm{s}$ & Measured \\
\hline Specific energy required to cut the sugarcane at base & 39.30 & $\mathrm{~mJ} / \mathrm{mm}^{2}$ & [24] \\
\hline Specific energy required for cut dry leaves & 30 & $\mathrm{~mJ} / \mathrm{mm}^{2}$ & Estimated $* * *$ \\
\hline Diameter of the cane stalk base & $23.97( \pm 3.84)$ & $\mathrm{mm}$ & Measured * \\
\hline Diameter of the cane stalk top & $22.15( \pm 3.84)$ & $\mathrm{mm}$ & Measured * \\
\hline Length of the cane stalk & $227.25( \pm 61.19)$ & $\mathrm{mm}$ & Measured * \\
\hline Billet length & 25 & $\mathrm{~mm}$ & Measured * \\
\hline Number of the dry leaves per stalk & $6( \pm 2)$ & Nos. & Measured * \\
\hline Average thickness a leaf & $0.84( \pm 0.21)$ & $\mathrm{mm}$ & Measured * \\
\hline Average width of a leaf & $28.5( \pm 12.25)$ & $\mathrm{mm}$ & Measured * \\
\hline Average length of a dry leaf & $124( \pm 38)$ & $\mathrm{mm}$ & Measured * \\
\hline Average total pressure of the extractor fan & 9.54 & $\mathrm{kPa}$ & Measured \\
\hline Average wind speed of the fan & 6.62 & $\mathrm{~m} / \mathrm{s}$ & Measured \\
\hline Average weight of the cane after loading to the trailer & $4.95( \pm 0.52)$ & $\mathrm{t}$ & Measured \\
\hline Average height of the trailer & 3.3 & $\mathrm{~m}$ & Measured \\
\hline Percentage of dry leaves & 7 & $\%(\mathrm{~W} / \mathrm{W})$ & Calculated wb \\
\hline Moisture content of dry leaves & 16 & $\%$ & Measured \\
\hline Bulk density of the cleaned cane after normal handloading & 340 & $\mathrm{~kg} / \mathrm{m}^{3}$ & Measured * \\
\hline $\begin{array}{c}\text { Bulk density of the cane with } 7 \% \text { dry leaves after } \\
\text { normal handloading }\end{array}$ & 232 & $\mathrm{~kg} / \mathrm{m}^{3}$ & Measured * \\
\hline $\begin{array}{c}\text { Bulk density of the cane with } 7 \% \text { dry leaves after } \\
\text { careful handloading }\end{array}$ & 335 & $\mathrm{~kg} / \mathrm{m}^{3}$ & Measured * \\
\hline
\end{tabular}

* One-year-old cane, Irrigated cultivation, SL96328 (Sugarcane variety); ${ }^{* *}$ Engine break power $176 \mathrm{hp}$ (based on furrow space is $1.4 \mathrm{~m}$ and average yield -54 tonne/ha); ${ }^{* * *}$ Based on data published in [37] and moisture content of the dry leaves; ${ }^{\mathrm{wb}}$ Wet basis.

\subsubsection{Harvesting Capacity}

Theoretical manual harvesting capacity of a person in $\mathrm{CCH}$ was $1.87 \mathrm{tcc} / \mathrm{da}$, but this could be increased to $8.55 \mathrm{tcc} / \mathrm{da}$ with CDLH since manual harvesting does not need to spend time for removing dry leaves. Therefore, CDLH can increase manual harvesting capacity significantly (Figure 5). 
At present, the harvesters are paid based on the weight of the harvested cane per day per person (According to the industry information one person can earn LKR1000-1500 (5.5-8.3 USD) per tonne of cane harvested in 2017). However, with CDLH, there was a potential to increase the harvester income since the harvester capacity was increased. Therefore, this would help to reduce the labor moving out from sugarcane harvesting while increasing the income level of the harvesters. Also, increasing the harvesting capacity would increase the harvesting rate by occupying a minimum number of laborers. Therefore, it will help to supply sugarcane and dry leaves to run the factory at the maximum capacity while increasing cogeneration.

Since CDLH is a novel concept and there is no machine adapted for CDLH, we did not discuss the capacity of the mechanical harvester in the CDLH system since the harvester capacity can be decided based on the requirement. But when applying CDLH for mechanical harvesting we would like to propose a redesign of the existing harvester for trimming the sugarcane from the base and remove the top, and then cane is loaded to trailers without chopping or removing the trash. However, the bulk density of the harvested cane with dry leaves would be reduced. Therefore, we recommend further research on the development of harvester without a chopping and cleaning system but including a system to improve the bulk density of the cane and dry leaves.

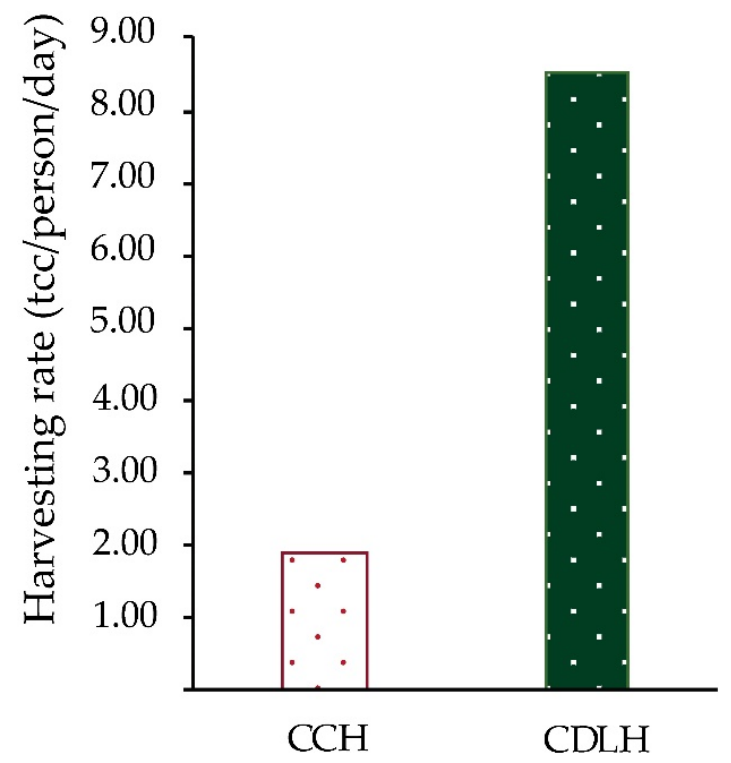

Figure 5. Manual harvesting rate (in $\mathrm{CCH}$-base, top cutting and dry leaves removing were done, in CDLH, only base and top cutting were done).

\subsubsection{Energy Consumption}

The results showed that the TE required in CCH was $5148 \mathrm{~kJ} / \mathrm{t}$ of clean cane supplied (tcc) to the factory and it was $5553 \mathrm{~kJ} / \mathrm{tcc}$ in CDLH when transported $1 \mathrm{~km}$ distance. Considering energy consumption for the different activities in harvesting as listed in Table 3, both CCH and CDLH show similar energy consumption for base cutting, top cutting, chopping, and cleaning assuming no significant water losses occurred during transportation. 
Table 3. Theoretical energy consumption for different activities in $\mathrm{CCH}$ and CDLH when transport harvested cane for $1 \mathrm{~km}$ distance.

\begin{tabular}{ccccc}
\hline Activity & & CCH & CDLH & CDLH (IBD) \\
\hline Base cut $(\mathrm{kJ} / \mathrm{tcc})$ & - & 17 & 17 & 17 \\
Top cut $(\mathrm{kJ} / \mathrm{tcc})$ & - & 14 & 14 & 14 \\
Chopping $(\mathrm{kJ} / \mathrm{tcc})$ & Cane & 123 & $123^{\mathrm{a}}$ & $123^{\mathrm{a}}$ \\
& Leaves & 3 & $3^{\mathrm{a}}$ & $3^{\mathrm{a}}$ \\
Cleaning $(\mathrm{kJ} / \mathrm{tcc})$ & & 3580 & $3580^{\mathrm{a}}$ & $3580^{\mathrm{a}}$ \\
Loading $(\mathrm{kJ} / \mathrm{tcc})$ & 32 & 35 & 35 \\
Transport $(\mathrm{kJ} / \mathrm{tcc} / \mathrm{km})$ & 1379 & 1781 & 1493 \\
\hline Energy consumption at the factory $(\mathrm{kJ} / \mathrm{tcc})$ & 0 & $3706^{*}$ & $3706^{*}$ \\
Energy consumption at the field $(\mathrm{kJ} / \mathrm{tcc})$ & $5148^{* *}$ & $1847^{* *}$ & $1559^{* *}$ \\
\hline \multicolumn{2}{c}{ Total $(\mathrm{kJ} / \mathrm{tcc}) * * *$} & 5148 & 5553 & 5265 \\
\hline
\end{tabular}

a In CDLH chopping and cleaning was done in the factory, therefore, this energy is supplied by using biomass energy; * Sum of "a", ** sum of the values without "a", tcc- tonnes of cleaned cane supply to the factory; ${ }^{* * *}$ When transported $1 \mathrm{~km}$ distance, IBD-Improved bulk density.

In this study, energy calculations were undertaken precisely on each specific activity because, in practice, the energy consumption values would be varied, since there are many effects which influence the energy use in cane cutting such as cutter blade velocity, cutting angle and moisture content of the cane [31,32]. Therefore, we assumed those effects are similar in both conditions. The base-cutting energy requirement was $16 \mathrm{~kJ} / \mathrm{tcc}$. During cutting energy calculations, we considered the specific cutting energy of the selected cane variety as $39.30 \mathrm{~mJ} / \mathrm{mm}^{2}$ [21]. Depending on the cutting angle and cutting speed, the specific energy requirement for cutting would vary between $40-120 \mathrm{~mJ} / \mathrm{mm}^{2}$ [31]. As reported by Mathanker et al., [8] the power requirement for a base cutter was $610 \mathrm{~kJ}$ per tonne of cane, and this value had been calculated based on the pressure and flow rate of the hydraulic component of the base cutter. Therefore, this value can be considered as total actual energy requirement which is not only for cutting the cane but overcoming the other barriers for cutting such as numerous cane stalks with different cutting angles, ground barriers such as soil, power losses due to friction and to keep higher safety factor. For calculation purpose, we assumed the specific energy of the top cutting and chopping (only billet making) is similar to the base cutting energy since there were no data.

As listed in Table 3, chopping had two operations, one was cane chopping, and the other was trash chopping at the same time. In chopping, we assumed all the cane stalks and dry leaves were arranged in a similar orientation before cutting. After chopping, the next step of cleaning took place at the system similar to the cleaning system of the combine-chopper harvester. But the only difference was the location of the chopping and cleaning system. In $\mathrm{CCH}$ the chopping and cleaning system is in a combine-chopper harvester, but in CDLH it is assumed to be located in the sugar factory before the shedder. Therefore, cutting energy in both cases was similar. However, some sugarcane breeders contributed in developing sugarcane varieties with self-stripping leaves for improving the conventional harvesting efficiency [38]. The sugarcane research institute of Sri Lanka has developed varieties such as SL88 116, SL 924997 targeting ease of manual harvesting. The use of those varieties may reduce the energy requirement for cleaning and chopping in $\mathrm{CCH}$. Thus, energy consumption for chopping and cleaning may vary in $\mathrm{CCH}$ and $\mathrm{CDLH}$. However, the use of self-stripping varieties reduces the biomass supply for energy generation in CDLH. Moreover, there are some sugarcane varieties have difficulty to remove the leaves due to high fiber. Use of those varieties could improve the biomass supply in CDLH and increase the energy consumption in $\mathrm{CCH}$. Even high-fiber varieties may content more energy and high potential to supply more biomass through CDLH. Therefore, the use of high-fiber varieties may have higher energy benefit in CDLH. However, it is necessary to study the development of agronomical and breeding properties in more depth after getting enough data such as the mechanical properties related to harvesting from different sugarcane varieties.

In loading, we needed to lift the sugarcane to $3.3 \mathrm{~m}$ height. CDLH added $7 \%$ more weight than $\mathrm{CCH}$ to the cane as dry leaves lead to higher loading energy for CDLH. The transport energy 
requirement was calculated considering the weight of the cane and biomass since the other factors affecting transport were assumed to be the same in both conditions. The transport energy consumption depends on the bulk density of the cane and biomass. In $\mathrm{CCH}$ the bulk density was high, so it can transport the maximum amount of the cleaned cane to the factory using a minimum run due to higher loading capacity. But in CDLH the bulk density was lower and required more runs to supply the same amount of the clean cane to the factory.

Finally, the TE consumption of the CDLH was higher compared to CCH since it needed additional energy for loading and transport sugarcane with dry leaves. In $\mathrm{CCH}$, all the mentioned operations were carried out in the field; hence, the TE requirement of $5.148 \mathrm{MJ} / \mathrm{tcc}$ should be supplied using conventional fuel such as diesel when transported $1 \mathrm{~km}$ distance. But in CDLH base cutting, top cutting loading and transportation was done in the field and chopping, and cleaning was done in the factory. Thus, energy consumption in CDLH in the field (diesel) was $1.847 \mathrm{MJ} / \mathrm{tcc}$, and it was $64 \%$ less than $\mathrm{CCH}$ (Table 3 and Figure 6.) at $1 \mathrm{~km}$ transportation distance. However, the actual transportation distance was more than $1 \mathrm{~km}$. Hence the energy need for transportation is increased with the transport distance. Therefore, after $9 \mathrm{~km}$ of transportation distance, the FE consumption of the CDLH had been increased than the $\mathrm{CCH}$ (Figure 7a). The TE consumption was increased with the transportation distance in both conditions but the increasing rate was higher in CDLH due to less loading capacity. From an energy point of view, CDLH with normal loading conditions is appropriate for the area where transportation distance is less than $9 \mathrm{~km}$. With improved bulk density, the FE consumption of the $\mathrm{CDLH}$ was less than the $\mathrm{CCH}$ until $25 \mathrm{~km}$ (Figure 7a). Therefore, CDLH had an advantage over $\mathrm{CCH}$ with IBD. EPCR also exponentially reduced with the transport distance however in all the cases EPCR of the CDLH was higher than CCH. The benefit of the CDLH had been increased with IBD from 15\% to $40 \%$ at $25 \mathrm{~km}$ distance. Therefore, with IBD we could increase the effective transportation distance up to more than $25 \mathrm{~km}$.

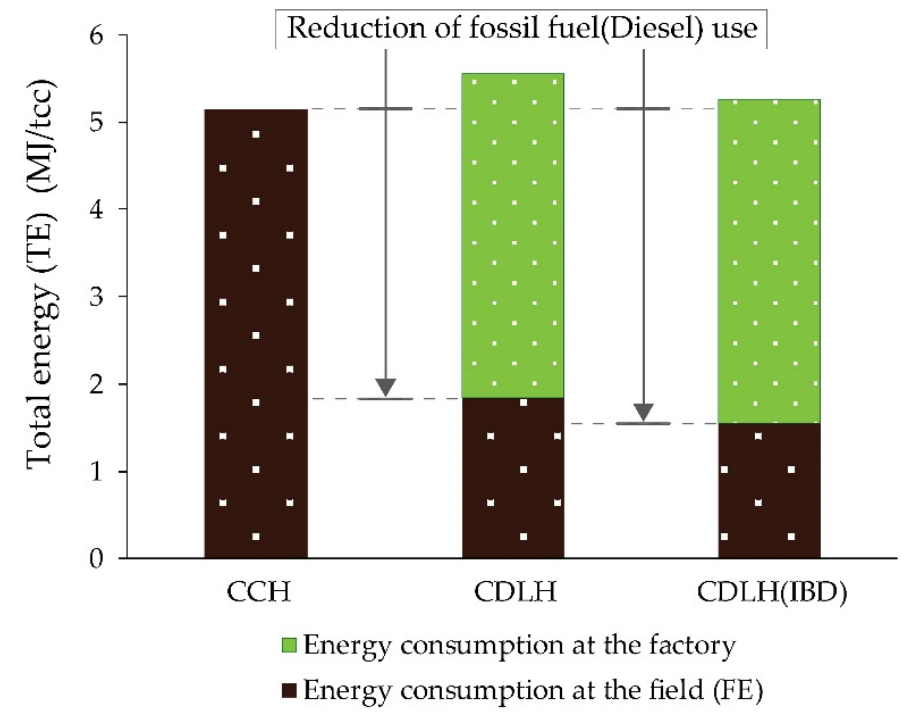

Figure 6. Comparison of total energy (TE) consumption in CCH and CDLH for $1 \mathrm{~km}$ transportation distance. FE depends on the transport distance.

\subsubsection{Energy Potential}

We evaluated energy potential based on the biomass availability, moisture content, and higher heating value of each biomass. The $\mathrm{CCH}$ only supplies bagasse for cogeneration, however, CDLH supplied cane and dry leaves to the factory. The average moisture content of the bagasse and dry leaves were $50 \%$ and $16 \%$, respectively. When supplying one tonne of clean cane stalked to the factory, there were $31 \%$ of bagasse after milling in $\mathrm{CCH}$. In CDLH other than bagasse there were about $7 \%$ additional dry leaves. The higher heating value (HHV) of the bagasse and dry leaves were $18.32 \mathrm{MJ} / \mathrm{kg}$ 
and $18.87 \mathrm{MJ} / \mathrm{kg}$ on a dry basis [30]. The HHV of the bagasse was reduced due to higher moisture content, and it was about $7.94 \mathrm{MJ} / \mathrm{kg}$ with $50 \%$ moisture. Therefore, the theoretical energy potential in $\mathrm{CCH}$ was $2460 \mathrm{MJ} / \mathrm{tcc}$, and CDLH was $3543 \mathrm{MJ} / \mathrm{tcc}$. Even CDLH showed higher energy consumption; it had a higher ability to produce more energy than $\mathrm{CCH}$. Therefore, the results showed that energy potential for consumption ratios (EPCR) of CCH and CDLH were 480 and 638, respectively at $1 \mathrm{~km}$ transportation distance and it was reduced with the transportation distance in both conditions. At $1 \mathrm{~km}$ transportation distance, CDLH showed 33.5\% EPCR benefit than CCH (Figure 7b). In the case of $25 \mathrm{~km}$ distance, EPCR benefit of the CDLH was reduced to $14 \%$ from $33.5 \%$. However, CDLH with IBD showed $34.04 \%$ benefit even at $25 \mathrm{~km}$ distance. In most of the areas in Sri Lanka the cane transportation distance is less than $25 \mathrm{~km}$. Therefore, CDLH has greater benefit than $\mathrm{CCH}$ in theory.

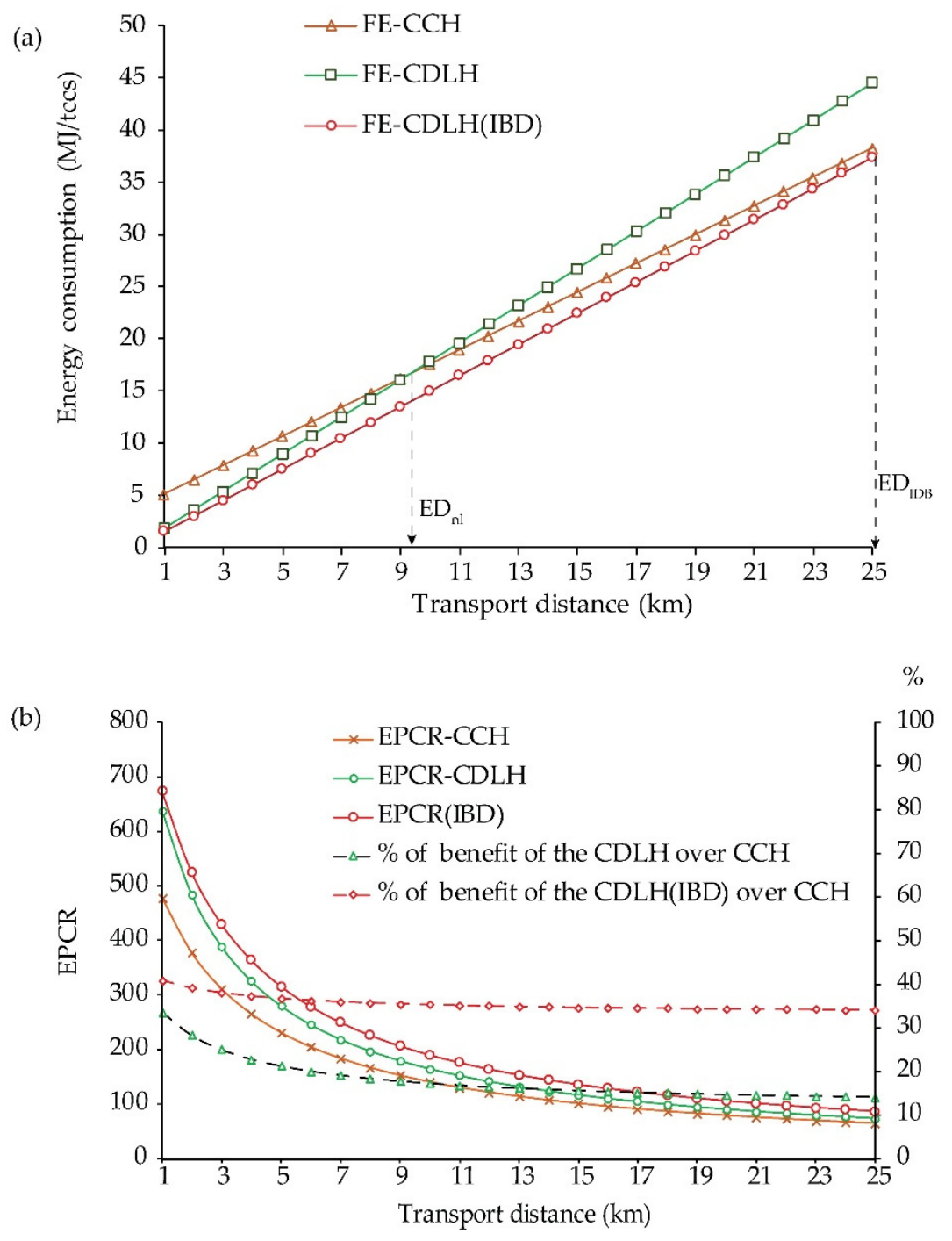

Figure 7. Energy comparison with the transport distance, (a) variation of field energy (FE) consumption with transport distance, (b) variation of energy potential to consumption ratio (EPCR) and benefit with transport distance; where, $\mathrm{ED}_{\mathrm{nl}}$ - effective transport distance with normal loading (from the energy point of view), $\mathrm{ED}_{\mathrm{IBD}}$ - effective transport distance with improved bulk density (IBD) (from the energy point of view).

\subsubsection{Potential Sugar Recovery}

The CCS percentage of the CCH and CDLH, $24 \mathrm{~h}$ after harvesting was $11.51 \%$ and $12.53 \%$, respectively. However, it was reduced to $9.62 \%$ in $\mathrm{CCH}$ and $11.78 \%$ in $\mathrm{CDLH} 72 \mathrm{~h}$ after harvest 
(Figure 8). As showed in Figure 8, the slope of the linear curve of the $\mathrm{CCH}$ was higher than the slope of the linear curve of the CDLH. Therefore, sugarcane harvesting without trash lost more sugar than CDLH with increasing processing delay. In general, while processing delay increases, the loss of CCS occurs, but the use of wetted dry sugarcane leaves reduces the CCS reduction rate over time [21]. With this statement, we can confirm that harvesting with trash would reduce post-harvest sugar degradation in CDLH. Also, the experimental results showed that the reducing sugar percentage of the billeted cane was higher compared to the whole cane harvesting. Therefore, the use of CDLH would help to maximize sugar recovery over $\mathrm{CCH}$.

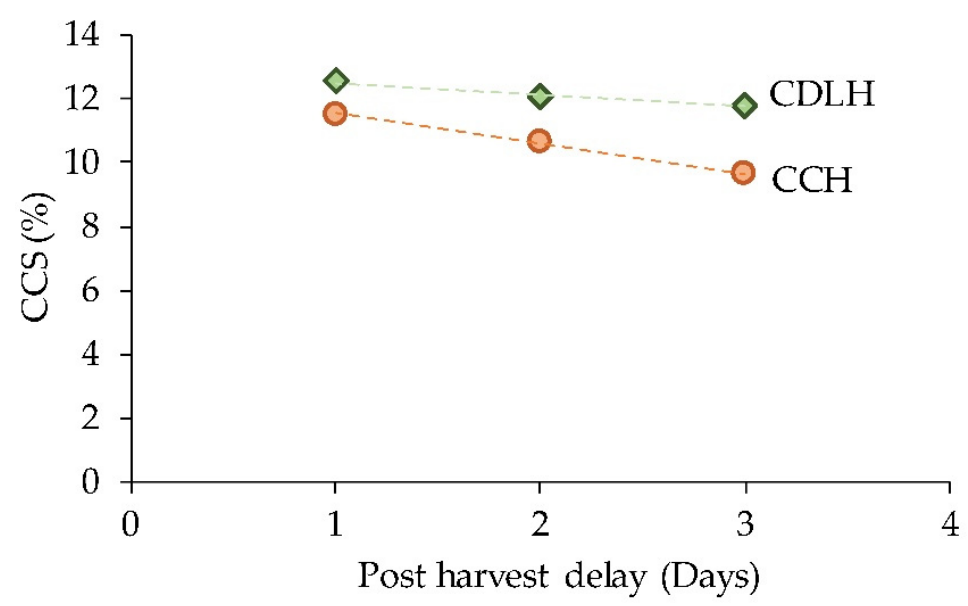

Figure 8. Effect of post-harvest delay on commercial cane sugar (CCS) in CDLH and CCT.

\subsection{Overall Comparison of $\mathrm{CCH}$ and $\mathrm{CDLH}$}

Overall results exhibited that CDLH required more energy compared to the CCH. In particular, CDLH required more transportation energy since the bulk of the transport had been increased. Therefore, with increasing transportation distance the energy consumption was increased. However, CDLH had many advantages over CCH. As shown in Figure 9, when the supply of sugarcane was equivalent to one tonne of clean cane, CDLH could produce an extra $0.02 \mathrm{t} / \mathrm{tcc}$ of sugar and $879 \mathrm{MJ} / \mathrm{tcc}$ electricity compared to the $\mathrm{CCH}$. The simple economics showed that the cost of processing one tonne of cleaned cane in CDLH was higher than the $\mathrm{CCH}$. But the cost of transportation energy compared to the net return of both conditions was very small. Therefore, the cost variation within the transportation distance was not significantly affecting the total cost. Even CDLH showed higher cost than the net return of the CDLH also higher. Figure 10 shows that the NPR of the CDLH was higher than the $\mathrm{CCH}$. However, we only considered the running cost when calculating the NPR, thus did not consider the initial investment on equipment installation. This is because in real practice many factors may affect initial investment considering the initial investment of the machinery, which is similar to the combine chopper-harvester cost. The initial investment for a combine chopper is about 25 million LKR (135,285 USD) and its productive life is 10 years with capacity of $184 \mathrm{tcc} / \mathrm{da}$ (based on the harvester maximum capacity). The cost can be added to the running cost as 68 LKR (0.368 USD)/tcc assuming a sugar factory may work 200 days per year. Thus, the investment cost of the machinery (68 LKR/tcc) could be lower compared to the running cost of the CDLH (Figure 10). The NPR of the CDLH was nearly two times higher than the $\mathrm{CCH}$. Therefore, it will not be difficult to recover the initial investment within a minimum possible time. However, to understand the detail initial investment, we need to undertake further studies regarding equipment design and implementation. Therefore, we recommend a detail economic analysis in a separate research to combine with this proposed novel concept. 

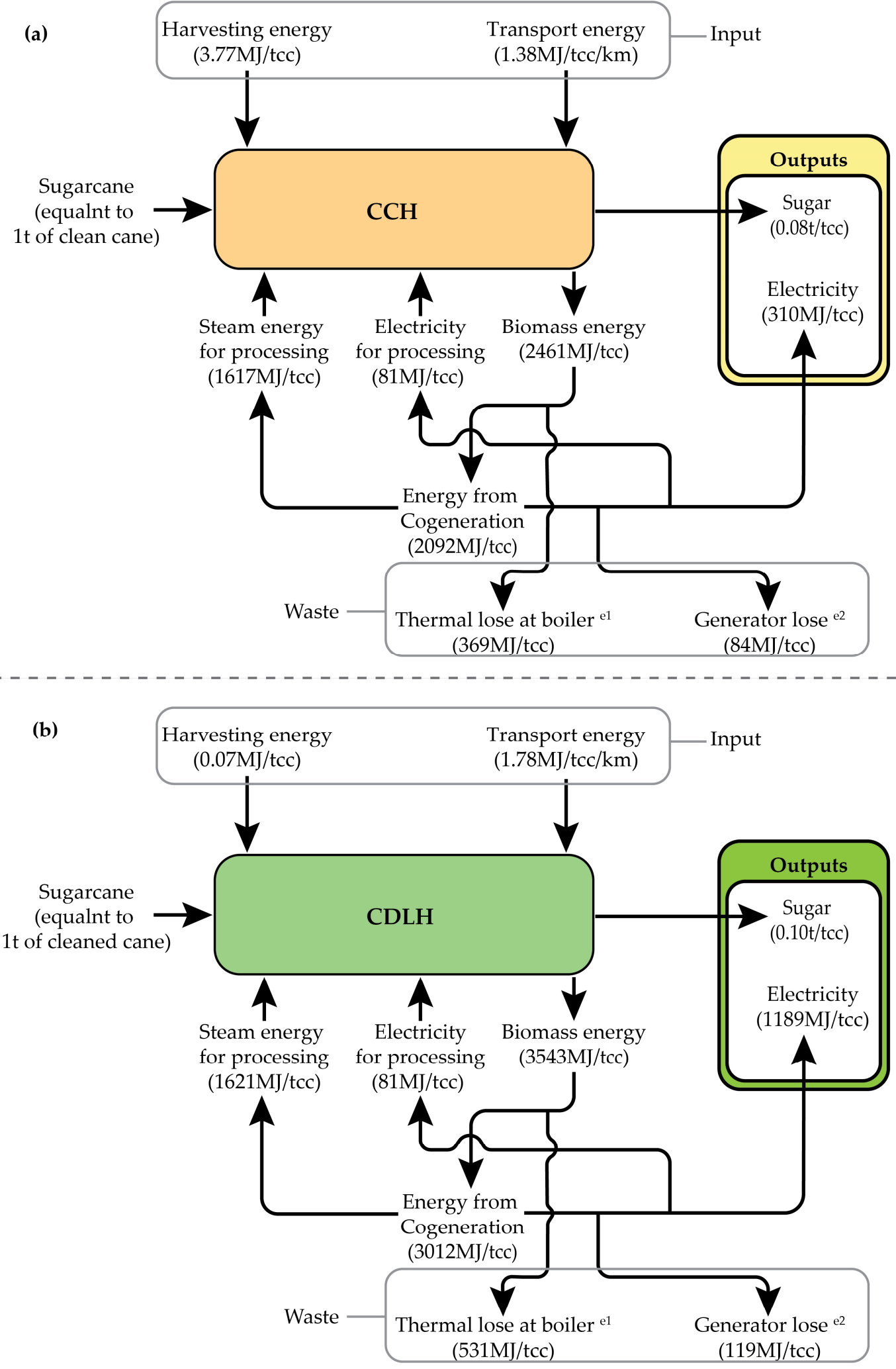

Figure 9. Energy use, bioenergy and sugar potential of the (a) $\mathrm{CCH}$ and (b) CDLH for one tonne of cleaned cane $(1 \mathrm{tcc})$ for $1 \mathrm{~km}$ transport distance. ${ }^{\mathrm{e} 1}$ Boiler thermal efficiency is $85 \%$, ${ }^{2}$ generator efficiency is $96 \%$. 


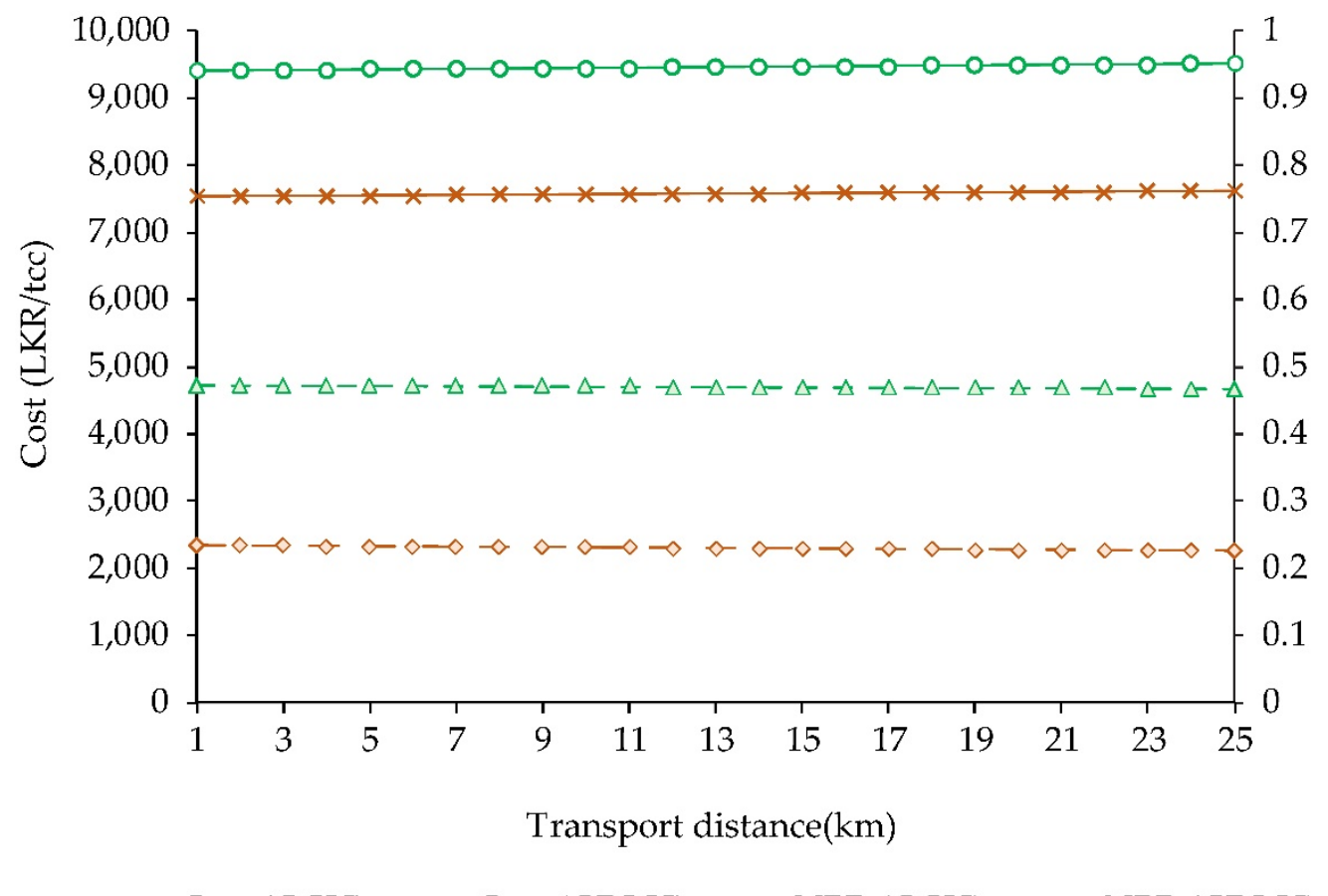

Figure 10. Variation of the cost of sugar production and net profit ratio with the transport distance.

A similar study was conducted to collect trash for bioethanol production by Cardoso et al., (2013) [39] and it showed that 70\% or less trash recovery through sugarcane harvesting would be more economical than bailing. Therefore, this study showed the theoretical evidence to develop a novel concept for maximum utilization of biomass while increasing sugar recovery with minimum energy requirement in the harvesting system. Since this study is theoretical, there is much uncertainty in some practical situations such as cane loading in the field and cane cleaning at the factory.

\section{Conclusions}

Sugarcane harvesting in Sri Lanka was studied, and the CDLH concept was developed in targeting to improve the biomass supply while minimizing post-harvest sugar losses. Sugarcane harvesting in Sri Lanka is under development, and much attention should be given to maximizing the productivity of the harvesting. The CDLH has many advantages compared to the CCH. Theoretically, CDLH can improve manual harvesting efficiency, biomass supply, and sugar recovery. CDLH required more energy for transporting cane to the factory, but it also created a system of supply of biomass to the factory. Therefore, from the energy point of view, CDLH has many advantages over CCH and the present sugarcane harvesting system could be redesigned based on the CDLH concept. In ideal conditions, the CDLH could produce more than $20 \mathrm{~kg}$ sugar and $879 \mathrm{MJ}$ electricity in the processing of one tonne of cleaned cane. With those advantages, the sugar industry has the opportunity to increase profit with reduced energy costs. Furthermore, FE consumption of the CDLH was reduced in general transport distance in Sri Lanka, therefore CDLH could reduce the diesel used for fieldwork while maximizing bioenergy. Furthermore, CDLH can be considered as an environmentally friendly green concept. Therefore, the novel CDLH concept could improve the existing harvesting system and have the potential for improving food and energy security in Sri Lanka. Finally, an experimental project is recommended with a prototype to investigate the economic and social effect of this concept to increase sugar production, energy utilization efficiency and environmental sustainability. 
Author Contributions: Conceptualization, T.A. (Thilanka Ariyawansha); methodology, T.A. (Thilanka Ariyawansha), B.K., S.A. and R.N.; analysis, T.A. (Thilanka Ariyawansha); resources, T.A. (Thilanka Ariyawansha), D.A., B.K. and R.N.; data curation, T.A. (Thilanka Ariyawansha), D.A., B.K., D.P., D.K., S.A. and N.S.; writing - original draft preparation, T.A. (Thilanka Ariyawansha) and W.B.; writing-review and editing T.A. (Thilanka Ariyawansha), R.N. and T.A. (Tofael Ahamed); supervision, R.N.; administration, D.A. and R.N.; funding, D.A. and R.N.; All authors have read and agreed to the published version of the manuscript.

Funding: This research was funded by Sugarcane Research Institute, Sri Lanka and the APC was funded by the University of Tsukuba, Japan.

Acknowledgments: Data collection was supported by Athula Sirideva, the Lanka Sugar Industries (Pvt) Ltd., Sevanagala, Sri Lanka, and all the staff of the mechanization technology division, Sugarcane Research Institute, Uda Walawe, Sri Lanka.

Conflicts of Interest: The authors declare no conflicts of interest.

\section{Nomenclature}

$\rho_{b}$

A

CCE

$C_{r}$

$C t E$

$D_{B C}$

$D_{n}$

DLCH

EPCR

Ef

El

Et

G

h

i

m

M

$\mathrm{McHC}$

$m_{c c}$

$\mathrm{MnHC}$

$m_{t}$

$m_{v}$

LHV

L

$l_{c}$

$l_{b}$

$P_{D L}$

$P_{t}$

$Q_{a}$

$S E_{c}$

$S E_{D L}$

TEC

$t_{d}$

TEP

$t_{h}$

$t_{S}$

$v$

$V_{h}$

$W_{c}$

$W_{C S}$

$Y_{u}$

Bulk density of the cane $\left(\mathrm{t} / \mathrm{m}^{3}\right)$

Cross-section area of the cut surface of the dry leaves $\left(\mathrm{mm}^{2}\right)$

Energy need for chopping cane (kJ/tcc)

Coefficient of rolling resistance

Energy needs to cut the sugarcane from base or top (J/tcc)

Average diameter of the cane stalk ( $\mathrm{mm}$ )

Diameter of each cutting/chopping point ( $\mathrm{mm}$ )

Dry leaves' cutting energy ( $\mathrm{kJ} / \mathrm{tcc})$

Energy potential to consumption ratio (No units)

Energy need for cleaning the cane $(\mathrm{kJ} / \mathrm{tcc})$

Loading energy for one tonne of clean energy ( $\mathrm{kJ} / \mathrm{tcc})$

Transport energy requirement $(\mathrm{kJ} / \mathrm{tcc} / \mathrm{km})$

Acceleration due to gravity $\left(9.81 \mathrm{~m} / \mathrm{s}^{2}\right)$

Height of the lift (m)

Number of cuts

Cane and dry leaves weight $(t)$

Moisture content of the biomass (in decimal)

Mechanical harvesting capacity (tcc/day)

Weight of clean cane $(\mathrm{t})$

Manual harvesting capacity (tcc/day/person)

Total weight $(\mathrm{t})$

Weight of the vehicle $(t)$

Lower heat of wet biomass at constant pressure $(\mathrm{MJ} / \mathrm{kg}$ )

Length (m)

Average length of the cane/dry leaves $(\mathrm{cm})$

Average length of the cane billet $(\mathrm{cm})$

Percentage of dry leaves (\%)

Total pressure $(\mathrm{kPa})$

Air flow rate $\left(\mathrm{m}^{3} / \mathrm{s}\right)$

Specific cutting energy $\left(\mathrm{J} / \mathrm{mm}^{2}\right)$

Specific cutting energy of the sugarcane trash $\left(\mathrm{J} / \mathrm{mm}^{2}\right)$

Total theoretical energy consumption for harvesting and supply $(\mathrm{MJ} / \mathrm{tcc})$

Working hours per $24 \mathrm{~h}(\mathrm{~h} / \mathrm{d})$

Total theoretical energy potential from bagasse and trash (MJ/tcc)

Time required to harvest one tonne of the cane (s)

Time required to harvest one cane stalk(s)

Volume of the wagon $\left(\mathrm{m}^{3}\right)$

Average speed of the harvester $(\mathrm{m} / \mathrm{s})$

Average weight of the one cane stalk (kg)

Average weight of a cane stalks at harvest $(\mathrm{kg})$

Unit yield along the raw $(\mathrm{kg} / \mathrm{m})$ 


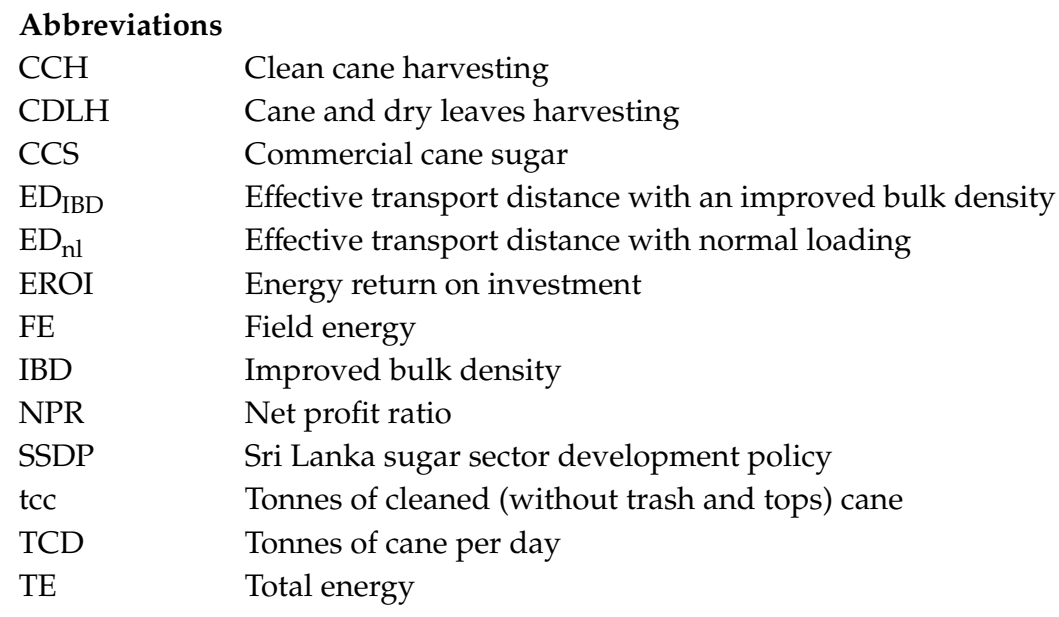

\section{References}

1. Brizmohun, R.; Ramjeawon, T.; Azapagic, A. Life cycle assessment of electricity generation in Mauritius. J. Clean. Prod. 2015, 106, 565-575. [CrossRef]

2. Figueroa-Rodríguez, K.A.; Hernández-Rosas, F.; Figueroa-Sandoval, B.; Velasco-Velasco, J.; Rivera, N.A. What has been the focus of sugarcane research? A bibliometric overview. Int. J. Environ. Res. Public Health 2019, 16, 3326. [CrossRef] [PubMed]

3. Yadav, R.L.; Solomon, S. Potential of developing sugarcane by-product based industries in India. Sugar Tech 2006, 8, 104-111. [CrossRef]

4. OECD/Food and Agriculture Organization of the United Nations. OECD-FAO Agricultural Outlook 2015; OECD Publishing: Paris, France, 2015; ISBN 9789264231900.

5. Kodituwakku, K.A.D. Economic Assessment of Sugarcane Cultivation in Sri Lanka in the Year 2017/18; Sugarcane Research Institute: Uda Walawe, Sri Lanka, 2017.

6. Keerthipala, A.P. Development of Sugar Industry in Sri Lanka. Sugar Tech 2016, 18, 612-626. [CrossRef]

7. Sugar Research Australia. Harvesting Best Practice Manual; Sugar Research Australia: Indooroopilly, Queensland, Australia, 2014.

8. Carvalho-netto, O.V.; Bressiani, J.A.; Soriano, H.L.; Fiori, C.S.; Santos, J.M.; Barbosa, G.V.S.; Xavier, M.A.; Landell, M.G.A.; Pereira, G.A.G. The potential of the energy cane as the main biomass crop for the cellulosic industry. Chem. Biol. Technol. Agric. 2014, 1, 20. [CrossRef]

9. Mathanker, S.K.; Gan, H.; Buss, J.C.; Lawson, B.; Hansen, A.C.; Ting, K.C. Power requirements and field performance in harvesting energycane and sugarcane. Biomass Bioenergy 2015, 75, 227-234. [CrossRef]

10. Naseri, A.A.; Jafari, S.; Alimohammadi, M. Soil Compaction Due to Sugarcane (Saccharum officinarum) Mechanical Harvesting and the Effects of Subsoiling on the Improvement of Soil Physical Properties. J. Appl. Sci. 2007, 7, 3639-3648.

11. Mckillop, C. Extraneous Matter Prompts Australian Sugar Industry to Address Productivity and Harvesting Losses. Available online: https://www.abc.net.au/news/rural/2016-01-14/so-whats-the-extraneous-matterwith-sugar/7074424 (accessed on 27 November 2019).

12. Datir, S.; Joshi, S. Original Research Article Post Harvest Sugarcane Quality under Manual (Whole Cane) and Mechanical (Billet) Harvesting. Int. J. Curr. Microbiol. Appl. Sci. 2015, 4, 204-218.

13. Smithers, J. Review of sugarcane trash recovery systems for energy cogeneration in South Africa. Renew. Sustain. Energy Rev. 2014, 32, 915-925. [CrossRef]

14. Deepchand, K. Characteristics, present use and potential of sugar cane tops and leaves. Agric. Wastes 1986, 15, 139-148. [CrossRef]

15. Holden, J.; McGuire, P. Irrigation of Sugarcane Manual; Sugar Research Australia: Indooroopilly, Queensland, Australia, 2014.

16. Tieppo, R.C.; Andrea, M.C.S.; Gimenez, L.M.; Romanelli, T.L. Energy demand in sugarcane residue collection and transportation. Agric. Eng. Int. CIGR J. 2017, 22, 52-58. 
17. Cesar, P.; Trivelin, O.; Coutinho, H.; Franco, J.; Otto, R.; Ferreira, D.A.; Vitti, A.C.; Faroni, C.E.; Oliveira, E.C.A.; Cantarella, H. Impact of sugarcane trash on fertilizer requirements for São Paulo, Brazil. Sci. Agric. 2013, 70, 345-352.

18. Guerra, J.P.; Cardoso, F.H.; Nogueira, A.; Kulay, L. Thermodynamic and environmental analysis of scaling up cogeneration units driven by sugarcane biomass to enhance power exports. Energies 2018, 11, 73. [CrossRef]

19. Lisboa, I.P.; Cherubin, M.R.; Lima, R.P.; Cerri, C.C.; Satiro, L.S.; Wienhold, B.J.; Schmer, M.R.; Jin, V.L.; Cerri, C.E.P. Sugarcane straw removal effects on plant growth and stalk yield. Ind. Crop. Prod. 2018, 111, 794-806. [CrossRef]

20. Weerasinghe, H.A.; Ariyawansha, B.D.S.; Wijesuriya, A. Response of Sugarcane (Saccharum hybrid spp.) Varieties SL 96128 and SL 96328 to Nitrogen, Phosphorous and Potassium under Irrigation at Uda Walawe, Sri Lanka: A Preliminary Analysis. Sugarcane Sri Lanka 2017, 3, 11-16.

21. Solomon, S. Post-harvest deterioration of sugarcane. Sugar Tech 2009, 11, 109-123. [CrossRef]

22. Lane, J.H.; Eynon, L. Determination of Reducing Sugars by Fehling's Solution with Methylene Blue Indicator; Noram Rodger: London, UK, 1934.

23. Robertson, F.A.; Thorburn, P.J. Decomposition of sugarcane harvest residue in different climatic zones. Soil Res. 2007, 45, 1-11. [CrossRef]

24. Ariyawansha, K.; Abeyrathna, K. Energy Requirements for Base Cutting of Selected Sugarcane Verities in Sri Lanka. Sugarcaen Sri Lanka 2014, 1, 49-53.

25. Farman, A.C.; Ji, C.; Ahmed, A.T.; Irshad, A.M.; Guang, T.; Do, M.C. Comparison of mechanical properties of wheat and rice straw influenced by loading rates. Afr. J. Biotechnol. 2013, 12, 1068-1077.

26. ToolBox, E. Fans-Efficiency and Power Consumption Power Consumption. Available online: https://www. engineeringtoolbox.com/fans-efficiency-power-consumption-d_197.html (accessed on 15 August 2019).

27. Jokiniemi, T.; Suokannas, A.; Ahokas, J. Energy consumption in agriculture transportation operations. Eng. Agric. Environ. Food 2016, 9, 171-178. [CrossRef]

28. Carvill, J. Mechanical Engineer's Data Handbook; Butterworth-Heinemann: Burlington, MA, USA, 1994; ISBN 0-7506-1960-0.

29. Boundy, S.W.B.; Diegel, L.W.; Davis, S.C.D. Biomass Energy Data Book, 4th ed.; U.S. Department of Energy: Oak Ridge, TN, USA, 2011.

30. Rípoli, T.C.C.; Molina, W.F., Jr.; Rípoli, M.L.C.R. Energy Potential of Sugar Cane Biomass in Brazil. Sci. Agric. 2000, 57, 677-681. [CrossRef]

31. Hall, C.A.S.; Dale, B.E.; Pimentel, D. Seeking to understand the reasons for different energy return on investment (EROI) estimates for biofuels. Sustainability 2011, 3, 2413-2432. [CrossRef]

32. Zeljko, B.; Naim, A.; Neven, D.; Zvonimir, G. Sustainable Development of Energy, Water and Environment Systems. In Proceedings of the 3rd Dubrovnik Conference, 5 Toh Tuck Link, Singapore, 5-10 June 2007.

33. Rajput, R.K. Engineering Thermodynamics; Laxmi Publications: New Delhi, India, 2010; ISBN1 1934015148, ISBN2 9781934015148.

34. Shahid, B.; Mahmood, H.; Naeem, F.; Zafrullah, K.; Zulfiqar, A. Ratooning potential of different promising sugarcane genotypes at varying harvesting dates. J. Agric. Biol. Sci. 2013, 8, 437-440.

35. Maria, C.; Manhães, C.; Garcia, R.F. Visible Losses in Mechanized Harvesting of Sugarcane Using the Case IH A4000 Harvester. Am. J. Plant Sci. 2014, 2014, 2734-2740.

36. Wang, F.; Yang, G.; Ke, W.; Ma, S. Effect of Sugarcane Chopper Harvester Extractor Parameters on Impurity Removal and Cane Losses. IFAC-PapersOnLine 2018, 51, 292-297. [CrossRef]

37. Arzola, N.; García, J. Study of the behavior of sugarcane bagasse submitted to cutting. Dyna 2015, 82, 171-175. [CrossRef]

38. CTA. Self-stripping sugarcane. Spore 50 (1994). Available online: https://cgspace.cgiar.org/handle/10568/ 49360 (accessed on 12 March 2020).

39. Cardoso, T.D.F.; Cavalett, O.; Chagas, M.F.; De Morais, E.R.; Nunes, J.L.; Franco, H.C.J.; Galdos, M.V.; Scarpare, F.V.; Braunbeck, O.A.; Cortez, L.A.B.; et al. Technical and economic assessment of trash recovery in the sugarcane bioenergy. Sci. Agric. 2013, 70, 353-360. [CrossRef]

(C) 2020 by the authors. Licensee MDPI, Basel, Switzerland. This article is an open access article distributed under the terms and conditions of the Creative Commons Attribution (CC BY) license (http://creativecommons.org/licenses/by/4.0/). 